\title{
Exigências nutricionais de bezerros nelores lactentes ${ }^{1}$
}

\section{Mozart Alves Fonseca², Sebastião de Campos Valadares Filho ${ }^{3}$, Lara Toledo Henriques ${ }^{4}$, Pedro Veiga Rodrigues Paulino ${ }^{3}$, Edenio Detmann ${ }^{3}$, Emílio Alves Fonseca ${ }^{5}$, Pedro Del Bianco Benedeti $^{6}$, Leandro Diego da Silva ${ }^{6}$}

\author{
1 Pesquisa realizada com apoio do CNPq - Conselho Nacional de Desenvolvimento Científico e Tecnológico. \\ 2 Programa de Pós-Graduação em Zootecnia, DZO-UFV, Viçosa, MG, 36570-000. \\ ${ }^{3}$ Departamento de Zootecnia, UFV, Viçosa, MG, 36570-000. \\ 4 UFPB. \\ ${ }^{5}$ Programa de Graduação em Agronomia - UFV. \\ ${ }^{6}$ Programa de Graduação em Zootecnia, DZO-UFV, Viçosa, MG, 36570-000.
}

RESUMO - Este trabalho foi conduzido com o objetivo de avaliar as exigências de proteína, energia e macrominerais de bezerros nelores do nascimento aos 180 dias. Foram utilizados 20 bezerros (10 machos e 10 fêmeas) com peso corporal médio de $30 \pm 3 \mathrm{~kg}$. Imediatamente após o nascimento, quatro bezerros, dois machos e duas fêmeas, foram abatidos para estimar a composição corporal inicial dos animais restantes no experimento. Aos 90 dias, foram abatidos oito bezerros (quatro machos e quatro fêmeas), o restante dos animais abatidos aos 180 dias. Além do leite, os bezerros foram alimentados com silagem de milho à vontade e concentrado comercial fixado em no máximo 0,5 kg/animal/dia. Foram conduzidos dois ensaios de digestibilidade, aos 30 e 90 dias para estimar os consumos de energia dos bezerros. Após o abate, todos os bezerros tiveram suas meias-carcaças direitas dissecadas. Os conteúdos corporais de proteína, energia e minerais foram estimados pela equação $\mathrm{Y}=\mathrm{a}$. PCVZ ${ }^{\mathrm{b}}$, sendo PCVZ o peso de corpo vazio. A relação PCVZ/PC dos bezerros foi de 0,9622 e a de ganho (G) de PCVZ/GPC foi de 0,958. As exigências líquidas de proteína e energia aumentaram com o aumento do peso corporal, enquanto as de cálcio diminuíram. As exigências de proteína metabolizável para ganho de $1 \mathrm{~kg}$ de PC foram de 216,96 e 261,98 g para bezerros de 100 e 200 kg, respectivamente. Recomenda-se utilizar as seguintes equações para estimar os conteúdos corporais de bezerros Nelore lactentes: proteína $(\mathrm{g} / \mathrm{dia})=0,135 \times \mathrm{PCVZ}$ 1,0351; energia $(\mathrm{Mcal} / \mathrm{dia})=1,1798 \times \mathrm{PCVZ}$ 1,1805; cálcio $(\mathrm{g} / \mathrm{dia})=0,091$ $\times \mathrm{PCVZ}^{0,6019}$; fósforo $(\mathrm{g} / \mathrm{dia})=0,00894 \times \mathrm{PCVZ}^{0,9629}$; sódio $(\mathrm{g} / \mathrm{dia})=0,00126 \times \mathrm{PCVZ}^{0,9791}$; magnésio $(\mathrm{g} / \mathrm{dia})=0,000405$ $\times$ PCVZ $^{0,9827}$; potássio $(\mathrm{g} / \mathrm{dia})=0,00165 \times \mathrm{PCVZ}^{0,9364}$.

Palavras-chave: eficiência, energia, energia do leite, macrominerais, proteína

\section{Nutritional requirements of nursing Nellore calves}

\begin{abstract}
This experiment was carried out to evaluate the nutritional requirements of protein, energy and macro minerals for Nellore calves from birth to 180 days. A total of 20 calves, 10 males (M) and 10 females (F) with average body weight (BW) of $30 \pm 3 \mathrm{~kg}$ were used. Soon after birth, four (2 males and 2 females) calves were slaughtered to estimate initial body composition of animals that remained in the trial. At 90 days, another eight calves were slaughtered (4 males and 4 females), and the remaining animals were slaughtered at 180 days. Besides milk, the calves were fed with corn silage ad libitum and commercial concentrate set at a maximum of $0.5 \mathrm{~kg} /$ animal/day. Two digestibility assay were conducted at 30 and 90 days to estimate the energy intake of the calves. After slaughtered all calves had their right half-carcasses dissected. The content of protein, energy and minerals were estimated by the equation $\mathrm{Y}=\mathrm{a}$. $\mathrm{EBW}^{\mathrm{b}}$, where $\mathrm{EBW}$ is the empty body weight. The relationship EBW/BW of calves was 0.9622 and EBWG/BWG was 0.958, where G is the gain. The net requirements of protein and energy increased with increasing body weight, while calcium decreased. The metabolizable protein requirements for gain of $1 \mathrm{~kg} \mathrm{BW}$ were 216.96 and $261.98 \mathrm{~g}$ for calves with 100 and $200 \mathrm{~kg}$ respectively. The following equations are recommended to estimate the body content of preweaning Nellore calves: protein $(\mathrm{g} / \mathrm{day})=0.135 \times \mathrm{EBW}^{1.0351}$; energy $(\mathrm{Mcal} / \mathrm{day})=1.1798$ $\times \mathrm{EBW}^{1.1805}$; calcium $(\mathrm{g} /$ day $)=0.091 \times \mathrm{EBW}^{0.6019}$; phosphorus $(\mathrm{g} /$ day $)=0.00894 \times \mathrm{EBW}^{0.9629}$; sodium $(\mathrm{g} /$ day $)=0.00126$ $\times \mathrm{EBW}^{0.9791}$; magnesium $(\mathrm{g} /$ day $)=0.000405 \times \mathrm{EBW}^{0.9827}$; potassium $(\mathrm{g} /$ day $)=0.00165 \times \mathrm{EBW0} .9364$.
\end{abstract}

Key Words: efficiency, energy, lactating cows, milk energy, macromineral, protein 


\section{Introdução}

O desenvolvimento do bezerro está diretamente associado à quantidade de leite fornecida ao animal e ao período de aleitamento (Roy, 1990), uma vez que o leite é naturalmente o alimento desses animais em uma fase mais jovem e sua composição é compatível com a exigência nutricional neste estádio do desenvolvimento. Além disso, o trato digestivo destes animais está preparado para utilizar mais eficientemente alimentos na forma líquida (Ternouth \& Prior, 1970).

Segundo Rocha et al. (1999), no período de aleitamento, o ruminante comporta-se fisiologicamente como animal não-ruminante. Esta é a fase mais crítica, pois o animal apresentar limitações enzimáticas e ausência de síntese microbiana e isso torna a utilização de certas fontes energéticas e protéicas ineficientes. Os maiores problemas a ser contornados, quando se tenta substituir o leite por outro alimento em idade precoce são: ineficiência de sistemas enzimáticos capazes de hidrolisar outros carboidratos que não a lactose, outros lipídeos que não a gordura do leite (ácidos graxos de cadeia curta), bem como a necessidade fisiológica de uma proteína que, tal como a caseína, propicie a formação de um coágulo de boa consistência no abomaso. Portanto, a composição do leite tem a mesma importância que os demais alimentos utilizados em outras fases de criação de animais ruminantes.

Em sistemas de produção de gado de corte, os gastos envolvidos com a alimentação dos animais assumem grande importância e respondem por 70 a 90\% dos custos operacionais totais, dependendo fase de criação considerada e do nível de produção desejado (Valadares Filho et al., 2006). Assim, a avaliação das exigências de bezerros pode melhorar os critérios utilizados na alimentação destes animais, agregando conhecimento às fases de crescimento e contribuindo para o aumento da produção de carne com a consequente redução da idade de abate.

Dessa forma, objetivou-se com este trabalho avaliar as exigências de energia, proteína e macrominerais de bezerros nelores lactentes do nascimento aos 180 dias.

\section{Material e Métodos}

O experimento foi conduzido nas dependências do Departamento de Zootecnia da Universidade Federal de Viçosa, em Viçosa, Minas Gerais. Foram utilizados 20 bezerros Nelore filhos de vacas Nelore primíparas, com peso inicial ao nascimento de $30 \pm 3 \mathrm{~kg}$. Logo após o nascimento, um grupo de quatro bezerros (2 machos e 2 fêmeas) foi abatido para estimação da composição corporal inicial dos animais que permaneceram no experimento (grupo referência). Os outros 16 animais representaram, respectivamente, os grupos de 90 dias ( 8 bezerros) e de 180 dias ( 8 bezerros), todos alimentados à vontade. Aos 90 dias do nascimento, foram abatidos oito animais (4 machos e 4 fêmeas) - metade deles era proveniente de vacas alimentadas à vontade - e os oito animais restantes foram mantidos no experimento até os 180 dias. Metade desses animais restantes era provenientes de vacas alimentadas à vontade e o restante das vacas alimentadas no nível mantença.

Os animais foram mantidos em duas baias individuais adjacentes: uma destinada à vaca e a outra ao bezerro em esquema de creep feeding, com piso de concreto, providas de comedouro e bebedouro individuais de concreto, com área total de $60 \mathrm{~m}^{2}$, sendo $16 \mathrm{~m}^{2}$ cobertos. Adaptações foram feitas nas instalações de modo que as vacas não tivessem acesso ao conteúdo dos cochos dos bezerros nem eles ao conteúdo do cocho das vacas. Assim, foi possível a mensuração do consumo individual diário das vacas e dos bezerros.

Os animais foram alimentados uma vez ao dia, às $7 \mathrm{~h}$. A dieta fornecida aos bezerros foi silagem de milho à vontade e ração concentrada comercial específica para bezerros (Tabela 1).

A quantidade diária de concentrado foi fixada em $500 \mathrm{~g} /$ bezerro e as sobras permitidas em torno de $10 \%$ da quantidade ofertada na base da matéria natural. A disponibilização de água foi à vontade.

Tabela 1 - Composição química da silagem de milho e do concentrado usado para bezerros nelores lactentes

\begin{tabular}{lcc}
\hline Item (\%) & $\begin{array}{c}\text { Silagem } \\
\text { de milho }\end{array}$ & $\begin{array}{c}\text { Concentrado } \\
\text { comercial }\end{array}$ \\
\hline Matéria seca (MS) & 33,06 & 88,96 \\
Matéria orgânica (MO), \% MS & 92,00 & 90,15 \\
Proteína bruta (PB), \% MS & 6,31 & 22,51 \\
PIDN, \%PB1 & 18,40 & 28,15 \\
PIDA, \%PB & 13,31 & 13,46 \\
Extrato etéreo (EE), \% MS & 3,56 & 3,57 \\
FDN, \% MS & 60,93 & 27,04 \\
FDNp, \% MS & 57,76 & 16,71 \\
FDNcp, \% MS & 55,80 & 13,97 \\
CNFcp, \% MS & 26,34 & 50,10 \\
FDA, \% MS & 38,70 & 17,44 \\
FDAcp, \% MS & 34,45 & 10,83 \\
Lignina, \% MS & 5,51 & 4,51 \\
FDNi, \% MS & 22,26 & 0,96
\end{tabular}

PIDA - proteína insolúvel em detergente ácido; PIDN - proteína insolúvel em detergente neutro; FDN - fibra em detergente neutro; FDNp - FDN corrigida para proteína; FDNcp - FDN corrigida para cinzas e proteína; CNFcp - carboidratos não-fibrosos corrigidos para cinzas e proteína; FDA - fibra em detergente ácido; FDNi - FDN indigestível.

${ }^{1}$ BR-CORTE (Valadares Filho et al., 2006). 
O consumo foi mensurado diariamente, sendo coletadas amostras do volumoso, do concentrado e das sobras. Essas amostras foram identificadas e armazenadas em freezer a $-20^{\circ} \mathrm{C}$. Ao final de cada semana, uma amostra composta foi elaborada e pré-seca. Posteriormente outra amostra composta representando o período de 28 dias foi realizada, a partir da proporção do consumo de matéria pré-seca de cada semana daquele período. O concentrado comercial foi amostrado diretamente nos sacos da ração.

Todas as amostras, exceto aquelas com menos de 15\% de umidade, foram pré-secas em estufa de circulação forçada $\left(60^{\circ} \mathrm{C}\right)$ por 72 horas e moídas em moinho de facas tipo Willey, com peneira de $1 \mathrm{~mm}$, sendo posteriormente armazenadas em recipientes de plástico para posteriores análises laboratoriais.

Foram realizados dois ensaios de digestibilidade, ao final do primeiro e terceiro meses de vida. As fezes foram obtidas diretamente via coleta retal em três dias diferentes (4ㅜㅡ, 50 e 60 dias após início do fornecimento do indicador), às $6 \mathrm{~h}, 12 \mathrm{~h}$ e $18 \mathrm{~h}$. As fezes foram acondicionadas em pratos de alumínio e secas em estufa com ventilação forçada $\left(60^{\circ} \mathrm{C}\right)$ e, em seguida, moídas em moinho de facas (1 mm). Uma amostra composta foi obtida por animal, por meio das amostras de fezes obtidas nos três dias, em cada ensaio de digestibilidade.

Para quantificação da excreção fecal, foi utilizado o indicador LIPE ${ }^{\circledR}$, fornecido na dose diária de $250 \mathrm{mg}$ na forma de cápsulas durante cinco dias aos animais. A coleta foi iniciada a partir do quarto dia do fornecimento do indicador e as análises de LIPE ${ }^{\circledR}$ foram feitas no Laboratório de Nutrição Animal da Escola de Veterinária da UFMG.

Os animais foram pesados ao nascimento, data que marcou o início do experimento. Pesagens dos animais foram feitas semanalmente para mensuração do consumo de leite, a partir da técnica de pesagem do bezerro antes e após a mamada, conforme descrito por McCarter et al. (1991), a fim de se determinar também a energia contida no leite. Os bezerros foram separados das vacas no dia anterior à pesagem e deixados em jejum. No dia da pesagem, foram colocados juntos, novamente, com as vacas para que mamassem todo o leite residual produzido no dia anterior. Após o período de amamentação, foram separados outra vez das vacas. Sequencialmente, duas pesagens (antes e depois da mamada) foram realizadas, às $12 \mathrm{~h}$ e às $18 \mathrm{~h}$, obtendo-se assim, por diferença de peso dos bezerros, a quantidade de leite produzida no período de 12 horas, que posteriormente foi corrigida para 24 horas. Para a avaliação da composição do leite, duas amostras de leite, por vaca e por coleta (correspondendo ao leite matinal e vespertino), foram obtidas manualmente a cada 28 dias e encaminhadas ao Laboratório de Análises da Embrapa Gado de Leite. Dos sólidos totais do leite, foram obtidos os teores de gordura, proteína e lactose, de forma a permitir a determinação da quantidade de energia contida no leite, usando a fórmula descrita no NRC (2001): Energia (Mcal $/ \mathrm{kg})=0,0929 \times \mathrm{G}(\%)$ $+0,0547 \times \mathrm{PB}(\%)+0,0395 \times$ Lactose $(\%)$.

As análises bromatológicas foram realizadas conforme Silva \& Queiroz (2002) e o teor de proteína bruta (PB) foi obtido a partir do produto do $\mathrm{N}$ total pelo fator 6,25 . Os teores de fibra em detergente neutro (FDN), utilizando-se amilase e omitindo-se sulfito, nitrogênio insolúvel em detergente neutro (NIDN) e em detergente ácido (NIDA), foram obtidos de acordo com os protocolos descritos por Van Soest et al. (1991) e Licitra et al. (1996), respectivamente.

A concentração de energia da dieta, expressa em \% de NDT, foi calculada a partir das digestibilidades, segundo a fórmula recomendada pelo $\mathrm{NRC}$ (2001): $\mathrm{NDT}=\mathrm{PB}_{\mathrm{D}}+2,25$ $\times \mathrm{EE}_{\mathrm{D}}+\mathrm{CNF}_{\mathrm{D}}+\mathrm{FDN}_{\mathrm{cpD}}$, sendo que $\mathrm{PB}_{\mathrm{D}}, \mathrm{EE}_{\mathrm{D}}, \mathrm{CNF}_{\mathrm{D}} \mathrm{e}$ $\mathrm{FDN}_{\mathrm{cpD}}$ significam, respectivamente, proteína bruta digestível, extrato etéreo digestível, carboidratos nãofibrosos digestíveis e fibra em detergente neutro (corrigida para cinzas e proteína) digestível. A concentração de energia digestível (ED) da dieta foi obtida pela equação proposta pelo NRC (2001): $\mathrm{ED}(\mathrm{Mcal} / \mathrm{kg})=5,65 \times \mathrm{PB}_{\mathrm{D}}+9,39 \mathrm{EE}_{\mathrm{D}}+$ 4,15 $\times \mathrm{FDN}_{\mathrm{cp}}+4,15 \times \mathrm{CNF}_{\mathrm{D}}$. Os valores de energia metabolizável (EM), expressos em Mcal/kg da dieta, foram calculados como $\mathrm{EM}=\mathrm{ED} \times 0,96$ para leite $\mathrm{e} \mathrm{EM}=\mathrm{ED} \times 0,82$ para dieta sólida (NRC, 2000; 2001).

Os animais foram abatidos por concussão cerebral. Após o abate, o aparelho gastrintestinal de cada animal foi esvaziado e, juntamente com os órgãos, lavados. Os pesos foram somados aos das demais partes do corpo (carcaça, cabeça, couro, cauda, pés e sangue) para quantificação do peso de corpo vazio (PCVZ). A relação obtida entre o PCVZ e o peso corporal (PC) dos animais-referência foi utilizada para estimação do PCVZ inicial dos animais que permaneceram no experimento. Dentro de cada faixa de idade de abate (90 e 180 dias), foram escolhidos aleatoriamente dois animais para representar o grupo do qual foram retiradas amostras da cabeça e de membros, para posterior separação física do tecido mole, dos ossos e do couro. O peso de corpo vazio (PCVZ) foi obtido pelo somatório de todas as partes constituintes do corpo mais o sangue.

Após o abate, a carcaça de cada bezerro foi dividida em duas meias-carcaças, as quais foram pesadas e, em seguida, resfriadas em câmara fria a $-5^{\circ} \mathrm{C}$ durante 18 horas. Decorrido este tempo, as meias-carcaças direitas foram retiradas da câmara fria, pesadas e dissecadas, separando-se os tecidos muscular e adiposo do tecido ósseo. Em seguida, estes 
tecidos foram moídos conjuntamente e os ossos serrados em serra elétrica. Ao final do procedimento foram obtidas as amostras compostas de ossos da carcaça e músculo+gordura da carcaça. Os ossos da carcaça foram amostrados proporcionalmente às quantidades de ossos longos, vértebras e costelas. Posteriormente todas as amostras, devidamente processadas, foram encaminhadas ao laboratório para quantificação dos teores de proteína, gordura e minerais no corpo vazio.

As vísceras e os órgãos (rúmen, retículo, omaso, abomaso, intestino delgado, intestino grosso, gordura interna, mesentério, fígado, coração, rins, pulmão, língua, baço, carne industrial, esôfago, traqueia e aparelho reprodutor) foram moídos integralmente em cutter, de forma conjunta, sendo considerada amostra composta de órgãos e vísceras.

Amostras de sangue foram coletadas imediatamente após o abate, acondicionadas em recipiente plástico e levadas à estufa com ventilação forçada $\left(60^{\circ} \mathrm{C}\right)$. A seguir, foram moídas em moinho de bola e acondicionadas em recipientes para posteriores análises de matéria seca, nitrogênio total e extrato etéreo, conforme Silva \& Queiroz (2002).

As amostras compostas de órgãos e vísceras (200 g), de músculo+gordura (200 g), de couro (100 g), de ossos da carcaça (100 g), ossos dos pés (100 g), tendões (100 g), ossos da cabeça (200 g), tecido mole da cabeça (100 g), depois de seccionadas, foram acondicionadas em vidros com capacidade de $500 \mathrm{~mL}$ e levadas a estufa a $105^{\circ} \mathrm{C}$ por 72 horas, obtendo-se assim a matéria seca gordurosa (MSG).

Em seguida, as amostras foram submetidas a lavagens sucessivas com éter de petróleo e, depois de grande parte da gordura ser removida, foram reencaminhadas para estufa $105{ }^{\circ} \mathrm{C}$ por pelo menos 16 horas. A diferença de peso forneceu o pré-desengorduramento ou a matéria seca prédesengordurada (MSPD), cujo resultado foi adicionado ao EE residual na MSPD, para obtenção do teor total de gordura das amostras. Posteriormente, as amostras foram trituradas em moinho de bola, para quantificação dos teores de nitrogênio total, extrato etéreo e minerais, conforme descrição de Silva \& Queiroz (2002). A partir da diferença entre a composição inicial e final dos animais, estimaram-se as quantidades de proteína e extrato etéreo retidas no corpo, o que permitiu avaliar a energia retida.

Os conteúdos corporais de gordura e proteína foram determinados em função das concentrações percentuais destes nos órgãos e nas vísceras, no couro, no sangue, na cabeça (tecido mole e ossos), nos pés (tendões e ossos), e nas amostras da meia-carcaça direita. A avaliação da energia corporal foi obtida a partir dos teores corporais de proteína e gordura e seus respectivos equivalentes calóricos, conforme a equação preconizada pelo ARC (1980): CE = 5,6405X + 9,3929 Y, em que CE = conteúdo energético (Mcal); $\mathrm{X}=$ proteína corporal $(\mathrm{kg})$; $\mathrm{Y}$ = gordura corporal $(\mathrm{kg})$.

Os conteúdos de gordura, proteína, macrominerais e energia retidos no corpo dos bezerros lactentes foram estimados por meio de equações de regressão do conteúdo corporal destes constituintes, em função do PCVZ, segundo o ARC (1980), conforme o seguinte modelo: $Y=a \cdot X^{b}+e, e m$ que $\mathrm{Y}=$ conteúdo total de proteína $(\mathrm{kg})$, gordura $(\mathrm{kg})$, macrominerais (kg) e energia (Mcal) retido no corpo vazio; a e b = parâmetros de ajustamento da regressão do conteúdo de gordura, proteína, macrominerais e energia em função do PCVZ; X = PCVZ; e = erro aleatório.

Derivando-se as equações de predição do conteúdo corporal de energia e proteína em função do PCVZ, foram obtidas as equações de predição do conteúdo desses nutrientes por kg de ganho de PCVZ, que correspondem às exigências líquidas dos mesmos para ganho de um kg de PCVZ, sendo obtidas a partir de equação do tipo: $Y^{\prime}=a$ a. b. $\mathrm{X}^{\mathrm{b}-1}$, em que $\mathrm{Y}^{\prime}=$ exigências de energia e proteína no ganho de peso de corpo vazio; $\mathrm{a}$ e $\mathrm{b}=$ como descritos anteriormente; $\mathrm{X}=\mathrm{PCVZ}(\mathrm{kg})$.

A produção de calor em jejum ou as exigências de energia líquida para mantença $\left(E L_{m}\right)$ foram estimadas como o coeficiente da equação da regressão não-linear entre PC ( $\left.\mathrm{kcal} / \mathrm{PCVZ}^{0,75}\right)$ e o CEM $\left(\mathrm{kcal} / \mathrm{PCVZ}^{0,75}\right)$ em que $\mathrm{Y}=$ a. $\mathrm{e}^{\text {b.CEM }}, \mathrm{Y}=$ produção de calor $(\mathrm{PC})$ em kcal/PCVZ ${ }^{0,75}$; $\mathrm{a}=$ intercepto (exigência de energia líquida para mantença); $\mathrm{X}=$ consumo de energia metabolizável CEM $\left(\mathrm{kcal} / \mathrm{PCVZ}^{0,75}\right)$;

Para a conversão do PCVZ em peso corporal (PC), dentro do intervalo de pesos incluído no trabalho, calcularam-se as relações entre o PCVZ e o PC dos animais mantidos no experimento. Foram ajustadas equações de regressão entre a energia retida (ER, Mcal/dia) e o ganho diário de PCVZ (GPCVZ, kg/dia) para determinado PCVZ metabólico ( $\left.P C V Z{ }^{0,75}\right)$, a partir do método de modelos nãolineares (Procedimento Proc nlin do SAS - SAS Inst. Inc., Cary, NC), utilizando-se algoritmo iterativo de GaussNewton, sendo a equação geral representada pelo modelo: $\mathrm{ER}(\mathrm{Mcal} / \mathrm{dia})=\mathrm{a} \cdot \mathrm{PCVZ}^{0,75} \cdot \mathrm{GPCVZ}^{\mathrm{b}}$.

Para converter as exigências de energia líquida de ganho $\left(E L_{g}\right)$ em exigências de energia metabolizável para ganho $\left(E M_{g}\right)$, utilizaram-se dois fatores de eficiência de utilização da energia metabolizável para ganho $\left(\mathrm{k}_{\mathrm{g}}=0,69\right)$ para consumo de leite e $\mathrm{k}_{\mathrm{g}}=0,57$ para consumo de alimentos sólidos (NRC, 2001). Assim, o kg no período de 0 a 90 dias foi considerado $0,66(77 \times 0,69+23 \times 0,57)$ e, no período de 90 a 180 dias, foi $0,62(0,43 \times 0,69+57 \times 0,57)$, sendo 77 e $43 \%$ as porcentagens de MS de leite ingerida pelos bezerros nos respectivos períodos. As exigências de ED foram 
calculadas como EM/0,96 (NRC, 2001) e as exigências de NDT foram calculadas como ED/4,409.

Para a conversão das exigências líquidas de proteína para ganho em exigências de proteína metabolizável para ganho $\left(\mathrm{PM}_{\mathrm{g}}\right)$, calculou-se a eficiência ( $\mathrm{k}$ ), usando a equação descrita no NRC (2000), em que $k=83,4-0,114$ PCVZ. As exigências de proteína metabolizável para mantença $\left(\mathrm{PM}_{\mathrm{m}}\right)$ foram calculadas como $\mathrm{PM}_{\mathrm{m}}=4,0 . \mathrm{PC}^{0,75}$, conforme preconizado pelo BR-CORTE (Valadares Filho et al., 2010).

Para estimar as exigências de mantença de cada macroelemento mineral e, posteriormente, somá-las às exigências para ganho, no intuito de se obterem as exigências dietéticas totais, foram adaptadas as recomendações do ARC (1980) e do NRC (2000) para as perdas endógenas de Ca, P, Mg, K e Na, e a biodisponibilidade destes elementos nos alimentos, segundo o ARC (1980) e o NRC (2000).

Realizou-se também um contraste entre as variáveis de interesse com o intuito de comparar animais abatidos aos 90 e 180 dias.

\section{Resultados e Discussão}

Considerando que foram usados somente 20 bezerros, nessa pesquisa os dados de machos e fêmeas foram analisados em conjunto.

Para transformação do peso de corpo vazio em peso corporal (PC), foi utilizada a relação média PCVZ/PC obtida no experimento, que foi de 0,9622 . O valor para animais em crescimento é de 0,896 (Valadares Filho et al., 2006), contudo bezerros lactentes têm baixo consumo de alimentos sólidos e baixa proporção das câmaras fermentativas em relação ao TGI total e ao corpo. Segundo Church et al. (1988), estima-se que, ao nascimento, o rúmen-retículo ocupa cerca de $35 \%$ do TGI, o que representaria uma massa de $0,4 \%$ do PC, sendo este valor aumentado para 66\% (1,93\% do PC) aos 84 dias de idade. Segundo esses autores, o abomaso que representa $51 \%$ da massa do TGI ao nascimento, aos 84 dias equivale apenas a 19\%; corroborando com o processo de evolução do TGI de bezerros ruminantes ao longo de seu desenvolvimento corporal.

Para conversão das exigências de ganho de PCVZ (GPCVZ) em exigências para ganho de peso corporal (GPC), recomenda-se utilizar o valor médio de 0,958 , encontrado nessa pesquisa, que é próximo ao recomendado pelo NRC (2000), de 0,956.

Segundo Anderson et al. (1997), a ingestão de alimentos sólidos aumenta após o desaleitamento e o incremento no consumo de matéria seca é responsável pela aceleração nas mudanças físicas e fisiológicas do trato gastrintestinal do bezerro. A presença de alimentos sólidos aumenta a produção de ácidos graxos voláteis, acelerando a função metabólica do rúmen, a motilidade ruminal, o desenvolvimento epitelial e muscular do rúmen, além das mudanças anatômicas no trato gastrintestinal. O consumo de concentrado está associado a modificações histológicas na parede ruminal, relacionadas ao aumento de tamanho e densidade de papilas ruminais e da parede do rúmen. Já o volumoso estaria relacionado às mudanças anatômicas no TGI, ao aumento de tamanho e volume do rúmen-retículo e manutenção do pH ruminal.

Nos primeiros 90 dias, a alimentação foi constituída principalmente de leite (77\%), o que explica os menores consumos absolutos de matéria seca nesta fase. Nos 90 dias posteriores, o leite foi substituído gradualmente pelo consumo de concentrado e volumoso, os quais representaram em média 43\% (Tabela 2).

Os consumos expressos em \%PC foram abaixo dos recomendados pelo NRC (2000), que seriam de 3,53\% do PC. Todavia, espera-se menor consumo de MS para animais zebuínos, principalmente em razão da menor produção de leite das vacas.

Os teores de NDT foram de $89 \%$ e $70,81 \%$ para os períodos de 0 a 90 e de 90 a 180 dias após o parto, respectivamente. O elevado valor de NDT no período de 0 a 90 dias, refletido nos elevados coeficientes de digestibilidade (Tabela 3), pode ser explicado pelo alto valor energético do leite, que constituiu a maior parte da dieta dos bezerros. Nesta fase, o animal utiliza basicamente a lactose como fonte imediata de energia, vitaminas e cátions bivalentes. Até três semanas, as proteínas do soro e a lactose passam rapidamente para o intestino, e os coágulos de gordura e proteína são degradados gradualmente. Assim, os produtos passam lentamente ao intestino para completar sua digestão e absorção (Swenson \& Reece, 1996). Segundo esses autores, aos 56 dias os bezerros estão com o metabolismo intermediário desviado da utilização de glicose para a formação dos AGV passando do processo insulina-sensitivo para o insulina-

Tabela 2 - Consumo médio diário de bezerros nelores lactentes nos períodos de lactação

\begin{tabular}{|c|c|c|}
\hline & \multicolumn{2}{|c|}{ Consumo } \\
\hline & \multicolumn{2}{|c|}{ Período } \\
\hline & 0 a 90 dias & 90 a 180 dias \\
\hline CMS (kg/dia) & $1,12 \pm 0,05$ & $2,54 \pm 0,09$ \\
\hline CMS (\%PC) & $1,81 \pm 0,13$ & $2,35 \pm 0,13$ \\
\hline NDT (kg/dia) & $0,98 \pm 0,06$ & $1,80 \pm 0,11$ \\
\hline CEM (Mcal/dia) & $3,61 \pm 0,21$ & $6,51 \pm 0,39$ \\
\hline CEM $\left(\mathrm{kg} / \mathrm{PCVZ}^{0,75}\right)$ & $141,33 \pm 7,66$ & $194,03 \pm 13,51$ \\
\hline GMD (kg/dia) & $0,75 \pm 0,02$ & $1,06 \pm 0,04$ \\
\hline
\end{tabular}

CMS - consumo de matéria seca; NDT - nutrientes digestíveis totais; CEM consumo de energia metabolizável; GMD - ganho médio diário. 
Tabela 3 - Digestibilidade dos componentes da dieta em bezerros nelores lactentes nos períodos de lactação

\begin{tabular}{lcccr}
\hline Digestibilidade & \multicolumn{4}{c}{ Aparente total } \\
\cline { 2 - 5 } Período & MS & PB & EE & FDN $_{\mathrm{CP}}$ \\
\hline 0 a 90 dias & $74,00 \pm 1,35$ & $74,84 \pm 1,21$ & $85,11 \pm 1,63$ & - \\
90 a 180 dias & $71,46 \pm 1,58$ & $74,21 \pm 1,94$ & $93,57 \pm 1,09$ & $78,62 \pm 1,10$ \\
\hline
\end{tabular}

MS - matéria seca; PB - proteína bruta; EE - extrato etéreo; $\mathrm{FDN}_{\mathrm{cP}}$ - fibra em detergente neutro corrigida para cinzas e proteína; CNF = carboidratos não-fibrosos; NDT - nutrientes digestíveis totais.

resistente. A partir deste ponto, existe maior utilização e aproveitamento de volumosos como fonte de energia, concomitante com a maior estruturação dos componentes gástricos que são bem mais desenvolvidos no animal adulto.

Em função da pequena ingestão de alimentos sólidos, não foi possível estimar o coeficiente de digestibilidade da $\mathrm{FDN}_{\mathrm{cp}}$ (Tabela 3) na fase de 0 a 90 dias de pós parto.

Nos contrastes $(90 \times 180$ dias) testados entre as variáveis de interesse, observaram-se diferenças (Tabela 4) significativas $(\mathrm{P}<0,05)$ para o CMS $(\mathrm{kg} /$ dia e $\% \mathrm{PC})$, para o CEM(Mcal/diaekcal/PCVZ ${ }^{0,75}$ ), NDT(kg/dia)eGMD(kg/dia). Isso indica que, à medida que o animal avança na idade, ocorre a troca na ingestão da dieta basal. Paulatinamente, o leite é substituído pelos alimentos sólidos sem, contudo, reduzir seu desenvolvimento. Ou seja, com o avançar da idade, aumentam as exigências e os ganhos, como consequência da maior ingestão absoluta de energia.

Para as digestibilidades (Tabela 5), testando o mesmo contraste (90 dias $\times 180$ dias), observou-se que o coeficiente de digestibilidade da proteína não foi diferente $(\mathrm{P}>0,05)$, porém todos os outros (CDEE, CDFDN $\mathrm{CP}_{\mathrm{cp}}$, NDT) foram estatisticamente diferentes $(\mathrm{P}<0,05)$.

Observou-se ainda que as exigências de proteína aumentaram com o aumento do peso corporal dos bezerros (Tabela 6). Isso comprova que os animais nessa fase se encontram em crescimento acelerado. Assim, o turnover proteico desses animais foi intenso, ou seja, a atividade de crescimento intenso proporcionou alta atividade de síntese e degradação. As exigências de energia líquida também foram crescentes, à medida que houve aumento do peso corporal, indicando que, com o aumento do peso, houve acréscimo nos teores de gordura corporal (Tabela 6), corroborando dados de Gonçalves et al. (1991), Lana et al. (1992), Fontes (1995) e Paulino et al. (1999).

Signoretti et al. (1999), trabalhando com bezerros holandeses, encontraram comportamento semelhante para exigências de proteína e energia, porém os resultados foram levemente superiores aos encontrados neste trabalho. Para bezerros holandeses de $100 \mathrm{~kg}$ de PC, foram encontradas exigências de proteína de 180,54 g/kg GPCVZ e para bezerros de $200 \mathrm{~kg}$, as exigências de 182,22 g/kg GPCVZ. Esses resultados foram 9,14 e 7,76\% superiores aos encontrados nesta pesquisa, de 164,03 e 168,07 g/kg GPCVZ para bezerros Nelore (Tabela 7). Para as exigências de energia, simulando as mesmas condições anteriormente citadas, as exigências

Tabela 6 - Parâmetros das equações usadas para estimar os conteúdos corporais de energia, proteína e macrominerais de bezerros nelores lactentes

\begin{tabular}{lccc}
\hline Item & $\mathrm{a}$ & $\mathrm{b}$ & $\mathrm{s}_{\mathrm{xy}}$ \\
\hline Energia (Mcal) & 1,17980 & 1,1805 & 60,0358 \\
Proteína (kg) & 0,13500 & 1,0351 & 2,1526 \\
Cálcio (kg) & 0,09100 & 0,6019 & 0,4927 \\
Fósforo (kg) & 0,00894 & 0,9629 & 0,0533 \\
Magnésio (kg) & 0,00045 & 0,9827 & 0,0104 \\
Sódio (kg) & 0,00126 & 0,9791 & 0,0109 \\
Potássio (kg) & 0,00165 & 0,9364 & 0,0123 \\
\hline
\end{tabular}

$\mathrm{Y}=\mathrm{a} \cdot \mathrm{X}^{\mathrm{b}}$; em que $\mathrm{Y}=$ conteúdo total de proteína $(\mathrm{kg})$, gordura $(\mathrm{kg})$, macrominerais $(\mathrm{kg})$ e energia (Mcal) retido no corpo vazio; a e b = parâmetros de ajustamento da regressão do conteúdo de gordura, proteína, macrominerais e energia em função do PCVZ; $X$ = PCVZ.

Tabela 4 - Valores de probabilidade ( $P$-valor) para os consumos de matéria seca e de energia entre bezerros com 90 a 180 dias de idade

\begin{tabular}{cccccc}
\hline CMS (kg/dia) & CMS (\%PC) & NDT (kg/dia) & CEM $\left(\mathrm{kcal} / \mathrm{PCVZ}^{0,75}\right)$ & CEM (Mcal/dia) & GMD (kg/dia) \\
\hline$<0,0001$ & 0,0016 & $<0,0001$ & 0,0016 & $<0,0001$ & $<0,0001$ \\
\hline
\end{tabular}

Contraste testado: bezerros 90 dias $\times$ bezerros 180 dias. CMS - consumo de matéria seca; NDT - nutrientes digestíveis totais; CEM - consumo de energia metabolizável; GMD - ganho médio diário.

Tabela 5 - Valores de probabilidade ( $P$-valor) para os coeficientes de digestibilidade e o teor de NDT

\begin{tabular}{cccc}
\hline PB (\%) & $\mathrm{EE}(\%)^{1}$ & $\mathrm{FDN}_{\mathrm{cp}}(\%)$ & $\mathrm{CNF}(\%)^{1}$ \\
\hline 0,7785 & 0,0030 & $<0,0001$ & 0,0042 \\
\hline $\begin{array}{l}\text { Contraste testado: bezerros 90 dias } \times \text { bezerros 180 dias. PB - proteína bruta; EE - extrato etéreo; } \text { FDN }_{\mathrm{cp}} \text { - fibra em detergente neutro corrigida para cinzas e proteína; CNPF - } \\
\text { carboidratos não-fibrosos; NDT - nutrientes digestíveis totais. }\end{array}$
\end{tabular}


foram de 2,16 e 2,57 Mcal/kg PCVZ, resultados 32,07 e $28,60 \%$ inferiores aos encontrados neste trabalho que foram da ordem de 3,18 e 3,60 Mcal/kg PCVZ, respectivamente (Tabela 7). Araújo et al. (1998), em pesquisa com bezerros mestiços Holandês $\times$ Zebu, encontraram valores intermediários aos reportados de Signoretti et al. (1999) e aos deste trabalho. Para a proteína, os valores encontrados foram de 180 e 190 g/kg GPCVZ, porém a faixa de peso trabalhada foi maior, o que pode explicar a diferença entre as respostas. Para a energia, os valores encontrados foram também inferiores aos encontrados neste experimento. Araújo et al. (1998) observaram valores de 2,07 e 2,81 Mcal/kg PCVZ para os pesos (PC) de 100 e $200 \mathrm{~kg}$.

Para as exigências de macrominerais para ganho, os resultados foram inferiores àqueles encontrados por Signoretti et al. (1999) e Araújo et al.(1998). Para animais de $100 \mathrm{~kg}$ de PC e ganho de $1 \mathrm{~kg}$ de GPCVZ, esses autores verificaram, respectivamente, exigências de 15,63 e 16,51 g para cálcio, 10,06 e 8,55 g para fósforo, 0,35 e 0,28 g para magnésio, 1,24 e 1,12 g para sódio e 1,93 e 1,97 g para potássio. Entretanto, os comportamentos observados foram semelhantes para quase todos, ou seja, manutenção dos valores para os teores de $\mathrm{P}, \mathrm{Mg}, \mathrm{Na}$ e K e decréscimo nas exigências de cálcio. A redução observada para o cálcio está de acordo com a apresentada no BR-CORTE (Valadares Filho et al., 2006).

Foi obtida a seguinte equação para a energia retida: $\mathrm{ER}=0,0932$.PCVZ ${ }^{0,75}$.GPCVZ 0,9157 . Teoricamente, o coeficiente do GPCVZ deveria ser maior que um, pois à medida que ele aumenta o ganho de peso de corpo vazio, o animal deveria aumentar a deposição e exigência de energia. No entanto, provavelmente devido ao pequeno número de informações, não foi possível encontrar um coeficiente maior que um. Outro motivo pode residir na composição do ganho. Nesta fase a deposição de proteína é mais acentuada que a de gordura e esta por sua vez acarreta maior retenção de energia no corpo, visto que seu calor de combustão é maior. Ao agruparem grande quantidade de dados, Valadares Filho et al. (2006) obtiveram coeficiente maior que um e isso indica que maior quantidade de dados na estimativa desse modelo deveria gerar coeficiente mais próximo de um.

Os valores de cálcio obtidos para bezerros de $225 \mathrm{~kg}$ (Tabela 7), 6,44 g, são menores que os 6,63 g citados pelo BR-CORTE (Valadares Filho et al., 2010) para animais de $250 \mathrm{~kg}$ ganhando $0,5 \mathrm{~kg} / \mathrm{dia}$.

A quantidade relativamente constante de minerais na carcaça pode ser atribuída ao fato de a taxa de deposição de tecido ósseo na fase em questão estar diminuindo levemente, considerando que $99 \%$ do cálcio, $80 \%$ do fósforo e $70 \%$ do magnésio corporal estão presentes no esqueleto (NRC, 2000).

As exigências de proteína metabolizável de 507,72 g encontradas para bezerros lactentes de $225 \mathrm{~kg}$ (Tabela 8) são 4,6\% inferiores $(532,36 \mathrm{~g})$ àquelas simuladas com dados do BR-CORTE (Valadares Filho et al., 2010) para animais não-lactentes de $225 \mathrm{~kg}$ ganhando $1 \mathrm{~kg} /$ dia. Todavia, no banco de dados do sistema BR-CORTE, o peso corporal final mínimo foi de $151 \mathrm{~kg}$ para machos não-castrados.

De acordo com as exigências de energia metabolizável desses animais (Tabela 9), com o aumento do peso corporal do animal, aumenta também a participação das exigências de energia metabolizável de ganho na energia metabolizável total requerida pelo animal. Isso reflete a maior demanda energética para os processos vitais relacionados ao metabolismo, especialmente aqueles relacionados à deposição tecidual na composição do ganho.

Tabela 8 - Exigências líquidas, eficiência de utilização e exigências de proteína metabolizável de bezerros nelores lactentes

\begin{tabular}{lccccc}
\hline PC & PR $(\mathrm{g})$ & $\mathrm{K}$ & $\mathrm{PM}_{\mathrm{g}}$ & $\mathrm{PM}_{\mathrm{m}}$ & $\mathrm{PM}_{\text {total }}$ \\
\hline 50 & 160,09 & 0,78 & 196,83 & 75,21 & 272,04 \\
75 & 162,38 & 0,75 & 206,94 & 101,94 & 308,88 \\
100 & 164,03 & 0,72 & 216,96 & 126,49 & 343,45 \\
150 & 166,38 & 0,67 & 238,08 & 171,45 & 409,53 \\
200 & 168,07 & 0,61 & 261,98 & 212,73 & 474,71 \\
225 & 168,77 & 0,59 & 275,34 & 232,38 & 507,72 \\
\hline
\end{tabular}

$\mathrm{PCVZ}=\mathrm{PC} \times 0,9622 ; \mathrm{GPCVZ}=0,958 \mathrm{GPC} ; \mathrm{PM}_{\mathrm{m}}=4 \mathrm{~g} . \mathrm{PC}^{0,75} ; \mathrm{PM}_{\mathrm{g}}=\mathrm{PR} / \mathrm{K}$ $\mathrm{K}=83,4-0,114$ PCVZ para PCVZ $<300 \mathrm{~kg}$. PC - peso corporal; PR - exigências líquidas de proteína para ganho de PC (1 kg/dia); K - eficiência de utilização da proteína metabolizável.

Tabela 7 - Exigências líquidas de nutrientes de bezerros nelores lactentes (g/kg GPCVZ)

\begin{tabular}{|c|c|c|c|c|c|c|c|}
\hline \multirow[t]{2}{*}{$\overline{\mathrm{PC}}$} & \multicolumn{7}{|c|}{ Exigências líquidas } \\
\hline & Proteína $(\mathrm{g})^{1}$ & Energia $(\mathrm{Mcal})^{2}$ & Ca $(\mathrm{g})^{1}$ & $\mathrm{P}(\mathrm{g})^{1}$ & $\operatorname{Mg}(g)^{1}$ & Na $(g)^{1}$ & $\mathrm{~K}(\mathrm{~g})^{1}$ \\
\hline 50 & 160,09 & 2,80 & 11,72 & 7,46 & 0,37 & 1,14 & 1,21 \\
\hline 75 & 162,38 & 3,02 & 9,97 & 7,34 & 0,37 & 1,13 & 1,18 \\
\hline 100 & 164,03 & 3,18 & 8,89 & 7,27 & 0,37 & 1,12 & 1,16 \\
\hline 150 & 166,38 & 3,42 & 7,57 & 7,16 & 0,37 & 1,11 & 1,13 \\
\hline 200 & 168,07 & 3,60 & 6,75 & 7,08 & 0,36 & 1,11 & 1,11 \\
\hline 225 & 168,77 & 3,68 & 6,44 & 7,05 & 0,36 & 1,10 & 1,10 \\
\hline
\end{tabular}

PCVZ $=$ PC $\times 0,9622 ;{ }^{1} \mathrm{~g} / \mathrm{kg} \mathrm{GPCVZ;}{ }^{2} \mathrm{Mcal} / \mathrm{kg}$ GPCVZ. 
As exigências líquidas e dietéticas dos macroelementos minerais para mantença (Tabela 10) foram calculadas de acordo com as equações e biodisponibilidades citadas pelo NRC (2000) e ARC (1980), que também foram adotadas pelo BR-CORTE (Valadares Filho et al., 2010). Esses valores são baseados principalmente para cálcio, fósforo, magnésio e sódio nos pesos corporais e no caso do potássio em relação às excreções fecal, urinária e salivar e às perdas pela pele. Segundo BR-CORTE (Valadares Filho et al., 2010), o correto balanceamento cálcio:fósforo, se não for realizado, pode aumentar as exigências de mantença de cálcio, pois haverá aumento na excreção fecal e urinária de cálcio. No Brasil, ainda são escassos os trabalhos de pesquisa sobre as exigências nutricionais de minerais para mantença e os poucos encontrados na literatura apresentam valores muito variados e um tanto quanto discrepantes em relação aos adotados nos comitês internacionais de exigências nutricionais para ruminantes. Portanto, mais estudos são necessários para se estabelecerem as corretas necessidades dos animais focando também na interação entre os minerais e como estes podem afetar suas exigências em animais ruminantes.

As exigências dietéticas de minerais para ganho de peso corporal de bezerros Nelore lactentes encontradas neste experimento (Tabela 11) foram bem inferiores àquelas apresentadas no BR-CORTE (Valadares Filho et al., 2010).
Para o cálcio os valores encontrados foram mais discrepantes, cerca de $40 \%$ inferiores aos apresentados no BR-CORTE (Valadares Filho et al., 2010).

Em comparação aos dados de bezerros de $225 \mathrm{~kg}$ ganhando $1 \mathrm{~kg}$ de PC por dia, as exigências de fósforo, 15,22 g; magnésio, 6,53 g; sódio, 2,84 g; e potássio, 23,86 g (Tabela 12) foram semelhantes às descritas pelo sistema BR-CORTE (Valadares Filho et al., 2010).

O conhecimento geral das exigências nutricionais de bezerros permite melhor manejo nutricional, ou seja, estabelecer o momento correto e quais níveis de nutrientes devem ser fornecidos para alcançar os resultados pretendidos. Assim, estas informações poderiam ser úteis, por exemplo em uma simulação da necessidade ou não de fornecer suplemento a esses animais na fase de cria.

Tabela 11 - Exigências dietéticas de minerais (g/kg de ganho de peso corporal) de bezerros nelores lactentes em função do peso corporal

\begin{tabular}{lccccc}
\hline & \multicolumn{5}{c}{ Exigências dietéticas $(g / d i a)$} \\
\cline { 2 - 6 } PC & Ca & P & Mg & Na & K \\
\hline 50 & 22,46 & 10,51 & 2,09 & 1,20 & 1,16 \\
75 & 19,10 & 10,34 & 2,09 & 1,19 & 1,13 \\
100 & 17,03 & 10,24 & 2,09 & 1,18 & 1,11 \\
150 & 14,50 & 10,09 & 2,09 & 1,17 & 1,08 \\
200 & 12,93 & 9,97 & 2,03 & 1,17 & 1,06 \\
225 & 12,94 & 9,93 & 2,03 & 1,16 & 1,05 \\
\hline
\end{tabular}

Tabela 9 - Exigências de energia metabolizável e NDT para bezerros lactentes em função do peso corporais

\begin{tabular}{lcccc}
\hline PC & \multicolumn{3}{c}{ Exigências } \\
\cline { 2 - 5 } & EM $_{\mathrm{m}}($ Mcal/dia $)$ & EM $_{\mathrm{g}}($ Mcal/dia $)$ & EM $_{\text {total }}$ (Mcal/dia) & NDT (kg/dia) \\
\hline 50 & 1,88 & 2,48 & 4,36 & 1,03 \\
75 & 2,55 & 3,36 & 5,91 & 1,40 \\
100 & 3,16 & 4,17 & 1,33 & 1,73 \\
150 & 4,29 & 6,02 & 10,30 & 2,43 \\
200 & 5,32 & 7,47 & 12,79 & 3,02 \\
225 & 5,81 & 8,16 & 13,97 & 3,30 \\
\hline
\end{tabular}

PCVZ - PV × 0,9622; GPCVZ = 0,958 × GPC; k - 0.66 (50 a 100 kg); k - 0,62 (150 a 225 kg); EM -0.1 Mcal/PC

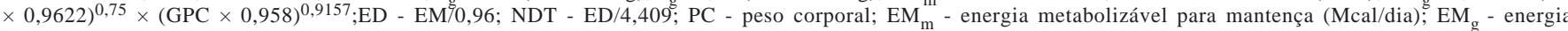
metabolizável para ganho (Mcal/dia); $\mathrm{EM}_{\text {total }}$ - exigências totais de energia metabolizável (Mcal/dia); NDT - nutrientes digestíveis totais.

Tabela 10 - Exigências líquidas (L) e dietéticas (D) de minerais para mantença de bezerros nelores lactentes (g/dia) em função do peso corporal

\begin{tabular}{|c|c|c|c|c|c|c|c|c|c|c|}
\hline \multirow[t]{2}{*}{ PC } & \multicolumn{2}{|c|}{$\mathrm{Ca}$} & \multicolumn{2}{|c|}{$\mathrm{P}$} & \multicolumn{2}{|c|}{$\mathrm{Mg}$} & \multicolumn{2}{|c|}{$\mathrm{Na}$} & \multicolumn{2}{|c|}{$\mathrm{K}^{1}$} \\
\hline & $\mathrm{L}$ & $\mathrm{D}$ & $\mathrm{L}$ & $\mathrm{D}$ & $\mathrm{L}$ & $\mathrm{D}$ & $\mathrm{L}$ & $\mathrm{D}$ & $\mathrm{L}$ & $\mathrm{D}$ \\
\hline 50 & 0,77 & 1,54 & 0,80 & 1,18 & 0,15 & 0,88 & 0,34 & 0,37 & 5,93 & 5,93 \\
\hline 75 & 1,16 & 2,32 & 1,20 & 1,76 & 0,23 & 1,35 & 0,51 & 0,56 & 8,34 & 8,34 \\
\hline 100 & 1,54 & 3,08 & 1,60 & 2,35 & 0,30 & 1,76 & 0,68 & 0,75 & 10,80 & 10,80 \\
\hline 150 & 2,31 & 4,62 & 2,40 & 3,53 & 0,45 & 2,65 & 1,02 & 1,12 & 15,58 & 15,58 \\
\hline 200 & 3,08 & 6,16 & 3,20 & 4,71 & 0,60 & 3,53 & 1,36 & 1,49 & 20,40 & 20,40 \\
\hline 225 & 3,47 & 6,94 & 3,60 & 5,29 & 0,68 & 4,50 & 1,53 & 1,68 & 22,81 & 22,81 \\
\hline
\end{tabular}

${ }^{1}$ Considerando CMS $=2 \%$ do PV. 
Tabela 12 - Exigências dietéticas totais de minerais para bezerros nelores lactentes em função do peso corporal (PC) Exigências dietéticas (g/dia) ${ }^{1}$

\begin{tabular}{lccccc}
\hline & \multicolumn{5}{c}{ Exigências dietéticas $(\mathrm{g} / \text { dia })^{1}$} \\
\cline { 2 - 6 } PC & Ca & P & Mg & Na & K \\
\hline 50 & 24,00 & 11,69 & 2,97 & 1,57 & 7,09 \\
75 & 21,42 & 12,10 & 3,44 & 1,75 & 9,47 \\
100 & 20,11 & 12,59 & 3,85 & 1,93 & 11,91 \\
150 & 19,12 & 13,62 & 4,74 & 2,29 & 16,66 \\
200 & 19,09 & 14,68 & 5,56 & 2,66 & 21,46 \\
225 & 19,88 & 15,22 & 6,53 & 2,84 & 23,86 \\
\hline
\end{tabular}

${ }^{1}$ Mantença + ganho de $1 \mathrm{~kg}$ de peso corporal.

Figueiredo et al. (2007), avaliando as respostas produtivas e econômicas de quatro sistemas de alimentação durante o ciclo produtivo de bovinos de corte (18, 24, 30 e 40 meses) recriados em pastagens tropicais como alternativa na redução na idade de abate, e baseando-se nas taxas de retorno do capital investido com a terra, concluíram que o abate aos 18 meses pode ser um alternativa economicamente mais vantajosa. Para que isso ocorra, ganhos médios diários anuais de mais de $700 \mathrm{~g} /$ dia é condição imprescindível, o que implica a necessidade da utilização do creep feeding.

$\mathrm{O}$ lento crescimento dos bezerros do nascimento à desmama e da desmama ao sobreano tem contribuído para o baixo desempenho observado nos sistemas de produção de bovinos de corte no Brasil (Cezar \& Euclides Filho, 1996). Esses sistemas são marcadamente associados a ganhos médios diários anuais na ordem de 200 g/dia e ciclos superiores aos 40 meses para idade de abate. Isto, por sua vez, pode reduzir em até $70 \%$ a produção anual de carne por unidade de área em comparação a animais de ciclos de 18 meses (Figueiredo et al., 2007).

Marques et al. (2005), avaliando 174 bezerros meiosangue Nelore $\times$ Red Angus, verificaram que os animais que receberam suplemento durante a fase de amamentação foram desmamados cerca de $9,4 \%$ mais pesados que aqueles que não receberam suplementação.

Segundo Silveira et al. (2001), bezerros desmamados com maior peso produzem carcaças mais pesadas ao final de um mesmo tempo de confinamento para produção de bovinos superprecoces. Isso, segundo os autores, poderia ser alcançado com uma estratégia de suplementação durante a lactação. Vaz \& Restle (2003) observaram que o ganho de peso na fase de aleitamento influencia o peso aos 12,18 e 24 meses.

Tendo em vista o conhecimento do fluxo energético relacionado à fase de cria (Tabela 13), pode-se simular a quantidade de energia disponível para os bezerros quando estes ingerem o leite. Tomando-se por base o NRC (2001), um bezerro em crescimento com PC ao nascimento de 35 kg possui exigências líquidas de energia de mantença de 1,24 Mcal/dia. Caso o objetivo do programa de manejo adotado fossem ganhos médios diários da ordem de $1,0 \mathrm{~kg} / \mathrm{dia}$, esses animais supririam suas exigências nutricionais alimentando-se apenas de leite até a sétima semana (49 dias) de vida, quando seu peso corporal atingiria a faixa dos $84 \mathrm{~kg}$ e suas exigências líquidas totais de energia contabilizariam 5,18 Mcal/dia (2,39 Mcal/dia para mantença e 2,79 Mcal/dia para ganho), o que implicaria em recomendação de suplementação a partir da sétima semana de vida do bezerro para este caso.

Nessa fase, os ganhos observados neste experimento foram de $0,75 \mathrm{~kg} / \mathrm{dia}$, que são condizentes com esses resultados, porém a suplementação iniciaria quando os animais atingissem $108 \mathrm{~kg}$ de PC, o que corresponderia à 14 a semana de vida (98 dias), como observado neste experimento, pois os animais se alimentavam basicamente de leite até os 90 dias de idade. Assim, recomenda-se a suplementação para que suas exigências nutricionais sejam atendidas e maiores ganhos diários possam ser alcançados.

Araújo et al. (1999), em pesquisa com bezerros de corte mestiços, verificaram que as exigências de energia líquida para mantença de um animal com $150 \mathrm{~kg}$ de PC são de 2,86 Mcal/dia e as de energia líquida para ganho de $1 \mathrm{~kg}$ de peso de corpo vazio, de 2,47 Mcal/dia, totalizando assim exigências diárias de 5,33 Mcal/dia. O leite supre essas quantidades de energia somente até a $14^{\mathrm{a}}$ semana da lactação. Assim, recomenda-se, com base nestas observações, iniciar a suplementação a partir desta fase.

Tabela 13 - Fornecimento das exigências nutricionais dos bezerros via leite

\begin{tabular}{lcc}
\hline $\begin{array}{l}\text { Semana } \\
\text { de lactação }\end{array}$ & PL (kg/dia) & $\begin{array}{c}\text { Energia secretada no } \\
\text { leite (Mcal/dia) }\end{array}$ \\
\hline 7,0 & 7,23 & 5,46 \\
8,0 & 7,25 & 5,47 \\
8,5 & 7,25 & 5,47 \\
9,0 & 7,25 & 5,47 \\
10,0 & 7,23 & 5,46 \\
12,0 & 7,15 & 5,40 \\
14,0 & 7,06 & 5,33 \\
16,0 & 6,94 & 5,24 \\
18,0 & 6,83 & 5,16 \\
22,0 & 6,62 & 5,00 \\
26,0 & 6,44 & 4,86 \\
\hline SL = semana de lactação, PL $=5,9579+0,4230 . S L \times \mathrm{e}^{(-0.1204 * \text { SL); Energia leite }=}$ \\
0,75 Mcal/kg.
\end{tabular}

\section{Conclusões}

Recomenda-se utilizar as seguintes equações para estimar os conteúdos corporais de nutrientes para bezerros Nelore de 0 a 180 dias: proteína (g/dia) $=0,135 \times \mathrm{PCVZ}^{1,0351}$; 
energia $(\mathrm{Mcal} /$ dia $)=1,1798 \times \mathrm{PCVZ}^{1,1805}$; cálcio $(\mathrm{g} / \mathrm{dia})=$ 0,091 × PCVZ ${ }^{0,6019}$; fósforo (g/dia) = 0,00894 × PCVZ ${ }^{0,9629}$; magnésio $(\mathrm{g} / \mathrm{dia})=0,00045 \times \mathrm{PCVZ}^{0,9827}$; sódio $(\mathrm{g} / \mathrm{dia})=$ $0,00126 \times \mathrm{PCVZ}^{0,9791}$; potássio $(\mathrm{g} / \mathrm{dia})=0,00165 \times$ PCVZ 0,9364

\section{Referências}

ANDERSON, K.L.; NAGARAJA, T.G.; MORRIL, J.L. Ruminal metabolic development in calves weaned conventionally or early. Journal of Dairy Science, v.70, n.5, p.1000-1005, 1997.

ARAUJO, G.G.L.; SIGNORETI, R.D.; COELHO DA SILVA, J.F. et al. Composição física da carcaça de bezerros da raça holandesa alimentados com dietas contendo diferentes níveis de concentrado. Revista Brasileira de Zootecnia, v.28, n.4, p.883-888, 1998.

ARAUJO, G.G.L.; COELHO DA SILVA, J.F. et al. Composição corporal e exigências liquidas de energia e proteína de bezerros alimentados com dietas contendo diferentes níveis de volumoso. Revista Brasileira de Zootecnia, v.27, n.5, p.1013-1022, 1998.

CEZAR, I.M.; EUCLIDES FILHO, K. Novilho precoce: reflexos na eficiência e economicidade do sistema de produção. Campo grande: EMBRAPA/CNPGC, 1996. 31p. (Documentos, 66).

CHURCH, D.C. The ruminant animal digestive phisiology and nutrition. New Jersey: Prentice \& Hall, 1988. 565p.

FIGUEIREDO, D.M.; OLIVEIRA, A.S.; SALES, M.F.L. et al. Análise econômica de quatro estratégias de suplementação para recria e engorda de bovinos em sistema pasto-suplemento. Revista Brasileira de Zootecnia, v.36, n5, p.1443-1453, 2007.

FONTES, C.A.A. Composição corporal, exigências líquidas de nutrientes para ganho de peso e desempenho produtivo de animais zebuínos e mestiços europeus x zebu. Resultados experimentais. In: SIMPOSIO INTERNACIONAL SOBRE EXIGENCIAS NUTRICIONAIS DE RUMINANTES, 1995, Viçosa, MG. Anais...Viçosa, MG: JARD, 1995. p.419-455.

GONÇALVES, L.C.; COELHO DA SILVA, J.F.; VALADARES FILHO, S.C. Composição do ganho de peso em taurinos, zebuínos, seus mestiços e bubalinos. Revista Brasileira de Zootecnia, v.20, n.3, p.413-419, 1991.

LANA, R.P.; FONTES, C.A.A.; PERON, A.J. et al. Composição corporal e do ganho de peso e exigências de energia, proteína e macrominerais (Ca, P, Mg, Na e K), de novilhos de cinco grupos raciais. 2. Exigências de energia e proteína. Revista Brasileira de Zootecnia, v.21, n3, p.528-537, 1992.

LICITRA, G.; HERNANDEZ, T.M.; VAN SOEST, P.J. Standartization of procedures for nitrogen fractionation of ruminant feeds. Animal Feed Science and Technology, v.57, p.347-358, 1996.
MARQUES, J.A.; ZAWADZKI, F.; CALDAS NETO, S.F. et al. Efeitos da suplementação alimentar de bezerros mestiços sobre o peso a desmama e taxa de prenhez de vacas multíparas Nelore. Archivos Latinoamericanos de Producción Animal, v.13, n.3, p.92-96, 2005.

McCARTER, M.N.; BUCHANAN, D.S.; FRAHM, R.R. Comparison of crossbred cows containing various proportions of Brahman in spring or fall calving systems: II. Milk production. Journal of Animal Science, v.69, n.1, p.77-84, 1991.

NATIONAL RESEARCH COUNCIL - NRC. Nutrient requirements of beef cattle. 7.ed. Washington, D.C.: National Academic Press, 2000. 242p.

NATIONAL RESEARCH COUNCIL - NRC. Nutrient requirements of dairy cattle. 7.ed. Washington, D.C.: National Academic Press, 2001. 381p.

PAULINO, M.F.; FONTES, C.A.A.; JORGE, A.M. et al. Composição corporal e exigências de macroelementos minerais ( $\mathrm{Ca}, \mathrm{P}, \mathrm{Mg}$, $\mathrm{Na}$ e K) de bovinos não castrados de quatro raças zebuínas. Revista Brasileira de Zootecnia, v.28, n.3, p.634-641, 1999.

ROY, J.H.B. The calf. 5.ed. London: Butterworths, 1990. v.1. 258p.

SIGNORETTI, R.D.; COELHO DA SILVA, J.F. et al. Composição corporal e exigências liquidas de energia e proteína de bezerros da raça Holandesa alimentados com dietas contendo diferentes níveis de volumoso. Revista Brasileira de Zootecnia, v.28, n.1, p.195-204, 1999.

SILVA, D.J.; QUEIROZ, A.C. Análise de alimentos (métodos químicos e biológicos). 3.ed. Viçosa, MG: Imprensa Universitária - Universidade Federal de Viçosa, 2002. 165p.

SILVEIRA, A.C.; ARRIGONI, M.B.; OLIVEIRA, H.N. et al. Produção de novilho superprecoce. In: SIMPOSIO DE PRODUCAO DE GADO DE CORTE, 2., 2001, Viçosa, MG. Anais... Viçosa, MG: SIMCORTE, 2001. p.37-54.

SWENSON, M.J.; REECE, W.O. Dukes fisiologia dos animais domésticos. 11.ed. Guanabara Koogan, 1996. 842p.

TERNOUTH, J.H.; PRYOR, W.J. The effect of early weaning rations upon the efficiency of growth and carcass production with some observations on the development of forestomachs in calves. Journal of Animal Science, v.74, p.559-569, 1970.

VALADARES FILHO, S.C.; PAULINO, P.V.R.; MAGALHÃES, K.A. Exigências nutricionais de zebuínos e tabelas de composição de alimentos - BR-CORTE. Viçosa, MG: UFV, DZO, 2006. 142p.

VAN SOEST, P.J; ROBERTSON, J.B.; LEWIS, B.A. Methods for dietary fiber, neutral detergent fiber, and nonstarch polyssacharides in relation to animal nutrition. Journal of Dairy Science, v.74, p.3583-3590, 1991.

VAZ, F.N.; RESTLE, J. Ganho de peso antes e após os sete meses no desenvolvimento e nas características de carcaça e carne de novilhos charolês abatidos aos dois anos. Revista Brasileira de Zootecnia, v.32, n.3, p.699-708, 2003. 